\title{
Agar as a Carbon Source in Relation to the Isolation of Lactose Non-utilizing Mutants of Aspergillus nidulans
}

\author{
By M. A. PAYTON AND C. F. ROBERTS \\ Department of Genetics, University of Leicester, Leicester LE1 7RH
}

(Received 12 October 1978)

\section{INTRODUCTION}

We have described how agar provides a significant source of carbon for the growth of Aspergillus nidulans (Payton et al., 1976) and shown that the inability of acetate nonutilizing ( $(\mathrm{ccu})$ mutants to grow on agar as sole carbon source suggests that agar is utilized by the organism through the pathway of acetate metabolism (Armitt et al., 1976). We have also demonstrated that the presence of agar in test media can generate spurious growth responses; in particular, certain $a c u$ mutants do not grow on carbon sources such as lactate, alanine, succinate, aspartate, glutamate (Payton et al., 1976) or lactamide (Payton, unpublished results) when agar is present in the medium. In contrast, the acu mutants do grow on these carbon sources when tested in liquid culture, unless the metabolic lesion in the mutant strain itself prevents growth on a particular carbon source.

These results prompt us to suggest a model for the growth of $A$. nidulans on agar in which the degradation of the agar polymers is effected by extracellular enzyme(s). Such a model is consistent with reports of extracellular enzymes from $A$. nidulans capable of degrading complex polysaccharides (Zonneveld, 1972a,b). We assume that the ability of agar to inhibit the utilization of other potential carbon sources requires at least the initial degradation of the agar polymers, though the precise mechanism by which the acu mutants are prevented from utilizing the alternative carbon sources is not understood. However, since the formation of extracellular enzymes by Aspergillus is usually catabolite-repressed (Bailey \& Arst, 1975; Cohen, 1977), it is likely that the agar-degrading enzymes are also subject to such carbon catabolite repression. Thus one might expect that the utilization of carbon sources which are strong catabolite repressors, such as glucose or sucrose, will not be susceptible to 'agarinhibition' due to repression of the synthesis of the enzyme(s) responsible for agar degradation. Conversely, the utilization of carbon sources which are weak catabolite repressors will exhibit 'agar-inhibition', that is, they will not support the growth of acu mutants when present in media solidified with agar.

If the hypothesis is correct, then mutant strains selected for no growth on carbon sources which are weak catabolite repressors may in some cases be analogous to the acu mutants. In particular, we thought it possible that certain strains isolated in this laboratory (Fantes \& Roberts, 1973) and elsewhere (Gajewski et al., 1972) as lactose non-utilizing mutants may not be defective in the catabolism of lactose itself but contain lesions in acetate metabolism.

\section{METHODS}

Strains. The strains of Aspergillus nidulans used were derived from the Glasgow stock and were in the R21 genetic background, pabaAl yA2 (requirement for p-aminobenzoic acid, yellow conidia). The mutants used and their associated enzyme lesions are given in Table 1.

Media. The defined minimal medium contained ( $\mathrm{gl}^{-1}$ in distilled water): $\mathrm{KNO}_{3}, 6 \cdot 0 ; \mathrm{KCl}, 0 \cdot 52 ; \mathrm{KH}_{2} \mathrm{PO}_{4}$, 1.52; and a trace elements solution (Armitt et al., 1976). The medium was brought to $\mathrm{pH} 6.5$ and supplemented with $p$-aminobenzoic acid $\left(1.0 \mathrm{mg} \mathrm{l}^{-1}\right)$. $\mathrm{MgSO}_{4} .7 \mathrm{H}_{2} \mathrm{O}$ was added separately to $0.52 \mathrm{~g}^{-1}$. All carbon sources were prepared as stock solutions in distilled water and sterilized by autoclaving at $110{ }^{\circ} \mathrm{C}$ for $20 \mathrm{~min}$. 
Media for plates were solidified with $1.5 \%(\mathrm{w} / \mathrm{v})$ Davis New Zealand agar and sterilized by autoclaving at $121{ }^{\circ} \mathrm{C}$ for $15 \mathrm{~min}$. The carbon source was added aseptically from stock solution to the cooled molten medium immediately before pouring the plates; these were dried before stab inoculation with conidia.

Media for liquid culture, containing the wetting agent Tween 80 diluted $10^{-5}(\mathrm{v} / \mathrm{v})$, were autoclaved at $121{ }^{\circ} \mathrm{C}$ for $15 \mathrm{~min}$ before adding $\mathrm{MgSO}_{4}$ and carbon source from stock solutions. The medium was then distributed aseptically in $5.0 \mathrm{ml}$ samples to capped $17 \mathrm{~mm}$ diam. test tubes. The cultures were inoculated with a standard loop of conidia and held at an angle during incubation on a rotary platform shaker.

Both plates and liquid cultures were incubated at $37^{\circ} \mathrm{C}$.

Assay for isocitrate lyase activity. Mycelium was harvested by filtration under suction on Whatman no. 1 filter paper and washed with distilled water and $0.02 \mathrm{M}$-phosphate buffer at $\mathrm{pH} 7 \cdot 0$. The mycelium was broken by sonication (MSE $150 \mathrm{~W}$ ultrasonic disintegrator) for $30 \mathrm{~s}$ in ice-cold buffer and cell debris was removed by centrifuging at $12000 \mathrm{~g}$ for $20 \mathrm{~min}$ at 0 to $4{ }^{\circ} \mathrm{C}$.

Isocitrate lyase (EC 4.1.3.1) was assayed spectrophotometrically at $37^{\circ} \mathrm{C}$ by following the formation of glyoxylate phenylhydrazone at $324 \mathrm{~nm}$. The assay mixture contained (in $1.0 \mathrm{ml}$ final vol.) $25 \mu$ mol imidazole buffer $\mathrm{pH} 6.8,5 \mu \mathrm{mol} \mathrm{MgCl}_{2}, 1 \mu \mathrm{mol}$ EDTA, $4 \mu \mathrm{mol}$ phenylhydrazine hydrochloride and $2 \mu \mathrm{mol} \mathrm{DL}$ isocitrate.

\section{RESULTS}

\section{Growth of acetate non-utilizing (acu) mutants on lactose}

The carbon sources whose utilization was found to be sensitive to 'agar-inhibition' (Payton et al., 1976) are all poor catabolite repressors (Bailey \& Arst, 1975), which is consistent with the hypothesis developed above. However, these carbon sources are also metabolized gluconeogenically and this raised the question whether the utilization of a carbon source which is a poor catabolite repressor but which is metabolized by glycolysis rather than by gluconeogenesis would exhibit 'agar-inhibition'. To test this, we examined the growth of the $a c u$ mutants on glucose, galactose or lactose, in the presence or absence of agar (Table 1). While these sugars are all utilized by glycolysis (McCullough et al., 1977), they differ in their effectiveness as carbon catabolite repressors. Glucose is a strong and galactose a moderate catabolite repressor, but lactose is a weak catabolite repressor in A. nidulans (Fantes \& Roberts, 1973; Arst \& Cove, 1973; Bailey \& Arst, 1975). The data (Table 1) show that while growth of the acu mutants on glucose and galactose is the same whether tested in liquid culture or on agar plates, their growth on lactose is inhibited when agar is present. That is, the utilization of glucose and galactose escapes 'agar-inhibition' while the utilization of lactose does not; this is good evidence supporting our hypothesis.

\section{Lactose non-utilizing mutants}

A number of strains of $A$. nidulans unable to grow on lactose are known. For example, Gajewski et al. (1972) isolated 24 lactose non-utilizing mutants, only six of which totally failed to grow on lactose. These six mutants, which grew normally on glucose or galactose, all failed to grow on acetate whilst the remaining 18 , which were leaky for growth on lactose, grew normally on acetate. In addition, five of the six strains did not utilize a number of other similar carbon sources, notably succinate. The model for 'agar-inhibition' suggests that these six strains were $a c u$ mutants.

In another study of lactose utilization by $A$. nidulans, Fantes(1972) sought mutants lacking $\beta$-galactosidase and isolated a number of strains defective in growth on lactose. Only one strain, designated lac105, showed all the characteristics expected of a mutant lacking $\beta$-galactosidase, i.e. no growth on lactose, normal growth on other sugars and very low $\beta$ galactosidase activity. However, strain lac105 proved to be a double mutant containing one mutation causing low $\beta$-galactosidase activity (bga mutation) and another mutation with no effect on $\beta$-galactosidase activity, yet causing poor growth on lactose (lac mutation). Recombinant strains carrying only the bga mutation grew as well as the wild type on lactose solid media though they did not grow in liquid culture. That is, deficiency of $\beta$-galactosidase 


\section{Table 1. Growth of A. nidulans acu mutants on glucose, galactose or lactose}

The results show the relative growth yields in response to carbon sources $(0.02 \mathrm{M})$ supplied in defined liquid medium or in the same medium solidified with agar. Growth yields were scored visually for the amount of mycelium produced in comparison to the wild-type strain R21. For each carbon source, yields were scored over the range +++ (good yield), + and $(+)$ (poor yields). Cultures were scored after $2 \mathrm{~d}$. While the growth of the wild type on each carbon source on agar plates or in liquid culture was similar, this does not imply that quantitative differences would not be found. Enzyme lesions are described in Armitt et al. (1976).

\begin{tabular}{|c|c|c|c|c|c|}
\hline & & & arbon sour & for grow & \\
\hline & & D-Glucose & Galactose & & \\
\hline Strain & Enzyme lesion & $\begin{array}{l}\text { Agar } \\
\text { plate }\end{array}$ & $\begin{array}{l}\text { Liquid } \\
\text { culture }\end{array}$ & $\begin{array}{l}\text { Agar } \\
\text { plate }\end{array}$ & $\begin{array}{l}\text { Liquid } \\
\text { culture }\end{array}$ \\
\hline R21 (wild-type) & - & $+t+$ & +++ & +++ & +++ \\
\hline acuA204 & Acetyl-CoA synthase & +++ & +++ & $(+)$ & +++ \\
\hline facB2-101 & Not known & $++t$ & +++ & + & $+t+$ \\
\hline acuC203 & Not known & +++ & +++ & + & $++t$ \\
\hline acuD202 & Isocitrate lyase & +++ & +++ & $(+)$ & +++ \\
\hline acuE20I & Malate synthase & +++ & +++ & + & +++ \\
\hline acuK248 & Malic enzyme & +++ & +++ & $(+)$ & +++ \\
\hline aсиM2-301 & Malic enzyme & +++ & +++ & $(+)$ & ++ \\
\hline acuF238 & PEP carboxykinase & +++ & +++ & + & +++ \\
\hline$a c u G 223$ & Fructose 1,6-bisphosphatase & +++ & +++ & + & +++ \\
\hline acuL217 & Not known & +++ & $++t$ & $(+)$ & $++t$ \\
\hline acuH206 & Not known & +++ & $++t$ & $(+)$ & +++ \\
\hline acuJ211 & Not known & +++ & +++ & $(+)$ & +++ \\
\hline acuN2-356 & Not known & +++ & +++ & + & +++ \\
\hline
\end{tabular}

apparently did not prevent the utilization of lactose. In the light of this result, two separate pathways were proposed for lactose utilization in $A$. nidulans; one requiring $\beta$-galactosidase activity and relatively unimportant during growth on lactose plates but necessary for growth on lactose in liquid culture, and an alternative pathway independent of $\beta$-galactosidase activity (Fantes \& Roberts, 1973). With our present knowledge of the utilization of agar as carbon source, the growth of a strain lacking $\beta$-galactosidase on lactose plates is not surprising since it is due to utilization of the agar, rather than utilization of the lactose. This can occur since lactose does not repress the synthesis of the agar-degrading extracellular enzymes.

The nature of the lac mutation in the lac105 strain was not studied further, though it was tentatively assigned to chromosome $\mathrm{V}$ by mitotic haploidization (Fantes, 1972). We felt that the lac mutation may be analogous to an acu mutation and have re-examined lac105.

\section{Is the lac mutation an acu mutation?}

Although the strain pabaA1 yA2; lac grew very poorly on lactose plates, it grew well on lactose in liquid culture, which is precisely the result obtained for the acu mutants. In addition, lac did not grow on certain gluconeogenic carbon sources in solid media, including acetate or alanine. Moreover, in liquid culture, lac did not grow on acetate but grew normally on alanine. This pattern of growth responses is identical to those we have previously described for several acu mutants (Payton et al., 1976) and indicates that lac is an acu mutation. The lac mutation is located on chromosome V (Fantes, 1972) and could be in one of five possible $a c u$ gene loci, $a c u H, A, D, G$ or $N$. Two of these loci, $a c u N$ and $a c u G$, can be ruled out since $a c u N$ mutants do not grow on alanine in liquid culture (Payton et al., 1976) whereas lac does, and acuG mutants do not grow on glycerol (Armitt et al., 1976) while lac does.

Two results prove that $l a c$ is a mutation at the isocitrate lyase structural gene locus ( $a c u D$ ) in chromosome V. First, cell-free extracts of lac grown on a mixture of sucrose and acetate 
were found to contain no isocitrate lyase activity. Second, there was no growth on acetate of a heterokaryon established between lac and acuD320, indicating non-complementation. Complementation was found between lac and strains characterizing each of the other 12 known acu loci (Armitt et al., 1976).

Thus the original strain lac105 isolated by Fantes (1972) was a double mutant containing one mutation $b g a A$ in a structural gene (linkage group III) for $\beta$-galactosidase (Fantes $\&$ Roberts, 1973), and a second mutation, originally called lac, in the structural gene locus $a c u D$ (linkage group V) for isocitrate lyase. The isolation of such a double mutant strain is not surprising since the mutagen was nitrosoguanidine and severe selection was applied in the screening programme.

\section{DISCUSSION}

The implications of the work described here are twofold. First, it is clear that 'agarinhibition ' of acu mutants is found not only on those carbon sources we reported previously (Payton et al., 1976) but also on lactose, a glycolytic carbon source. This may well reflect that 'agar-inhibition' is common to all carbon sources which are weak carbon catabolite repressors. We are unable to explain how agar inhibits growth of acu mutants on alternative carbon sources, except to propose that the $a c u$ mutants accumulate a toxic metabolite from agar degradation (Payton et al., 1976). However, it is certain that the selection of mutant strains unable to grow on agar plates containing carbon sources which are weak catabolite repressors may generate unexpected classes of mutant, specifically acu mutants.

Second, the demonstration that lac is actually an $a c u D$ mutant allele deficient in isocitrate lyase means that the contention that $A$. nidulans metabolizes lactose by two pathways (Fantes \& Roberts, 1973) is no longer tenable.

This work was supported by the Science Research Council (grant 1667-9); M.A.P. was in tenure of a research studentship from the same source.

\section{REFERENCES}

Armitt, S., McCullough, W. \& Roberts, C. F. (1976). Analysis of acetate non-utilizing ( $a c u)$ mutants in Aspergillus nidulans. Journal of General Microbiology 92, 263-282.

ArST, H. N. \& Cove, D. J. (1973). Nitrogen metabolite repression in Aspergillus nidulans. Molecular and General Genetics 126, 111-114.

BAILEY, C. \& ARST, H. N. (1975). Carbon catabolite repression in Aspergillus nidulans. European Journal of Biochemistry 51, 573-577.

COHEN, B. L. (1977). The proteases of Aspergilli. In Genetics and Physiology of Aspergillus, p. 281. Edited by J. E. Smith \& J. A. Pateman. London: Academic Press.

Fantes, P. A. (1972). Studies on the $\beta$-galactosidase system in Aspergillus nidulans. Ph.D. thesis, University of Leicester.

Fantes, P. A. \& Roberts, C. F. (1973). $\beta$-Galactosidase activity and lactose utilization in Aspergillus nidulans. Journal of General Microbiology $77,471-486$.

Gajewski, W., Litwinska, J., Paszewski, A. \& ChoJNACKI, T. (1972). Isolation and character- isation of lactose non-utilising mutants in Aspergillus nidulans. Molecular and General Genetics 116, 99-106.

McCullough, W., Payton, M. A. \& Roberts, C. F. (1977). Carbon metabolism in Aspergillus nidulans. In Genetics and Physiology of Aspergillus, p. 97. Edited by J. E. Smith \& J. A. Pateman. London: Academic Press.

Payton, M. A., McCullough, W. \& Roberts, C. F. (1976). Agar as a carbon source and its effect on the utilization of other carbon sources by acetate non-utilizing ( $\mathrm{acu}$ ) mutants of Aspergillus nidulans. Journal of General Microbiology 94, 228233.

ZONNEVELD, B. J. M. (1972 a). A new type of enzyme, an exo-splitting $\alpha$-1,3-glucanase from non-induced cultures of Aspergillus nidulans. Biochimica et biophysica acta 258, 541-547.

ZoNNEVELD, B. J. M. $(1972 b)$. Morphogenesis in Aspergillus nidulans. The significance of $\alpha-1,3-$ glucan of the cell wall and $\alpha$-1,3-glucanase for cleistothecium development. Biochimica et biophysica acta 273, 174-187. 